\title{
Conhecimentos sobre doenças de exclusão escolar temporária em creches e jardins-de-infância da área de influência do Centro de Saúde do Lumiar
}

Paula Nunes, ${ }^{*}$ Mara Silva Ferreira, ${ }^{* *}$ Bruno Heleno***

\section{RESUMO}

Objectivos: Caracterizar os conhecimentos dos educadores de infância e auxiliares de acção educativa sobre medidas de prevenção de infecções. Identificar sintomas ou doenças que, segundo os educadores de infância e auxiliares de acção educativa, justificam a exclusão escolar temporária.

Tipo de estudo: Não experimental, exploratório, descritivo, transversal.

Local: Creches e jardins-de-infância da área de influência do Centro de Saúde do Lumiar (Lisboa).

População: Educadores de infância e auxiliares de educação.

Métodos: Aplicação de questionário auto-preenchido a educadores de infância e auxiliares de educação que exerciam a sua actividade no período de 01/05/2009 a 31/06/2009 em creches/jardins-de-infância da área de influência do Centro de Saúde do Lumiar. Resultados: Das 31 instituições convidadas, 24 aceitaram participar no estudo (267 profissionais). Foram correctamente preenchidos 223 inquéritos (83,5\%), a idade média da população estudada foi 37,4 anos, 50,2\% dos profissionais afirmaram ter recebido formação em doenças contagiosas da infância. A causa mais apontada como responsável por doenças contagiosas na criança foi o ambiente fechado dos infantários (72,2\%). A lavagem das mãos foi referida por $94,2 \%$ dos profissionais como medida preventiva de infecções. A febre que não cede aos antipiréticos foi considerada como factor de exclusão por $91,9 \%$ dos inquiridos. A falta de ar não foi considerada por $21,5 \%$ dos inquiridos como motivo de exclusão. A diarreia com sangue foi o mais referido dos sintomas gastrointestinais (88,8\%). A escarlatina e o sarampo foram apontados por $97,8 \%$ dos profissionais como motivo de exclusão escolar. Das doenças que justificam exclusão escolar, a meningite foi a mais referida (93,3\%).

Conclusões: Os sintomas mais valorizados pelos profissionais de educação nem sempre coincidem com os considerados pelos profissionais de saúde, o que pode condicionar o afastamento escolar não fundamentado. A nível institucional poderá ser útil o desenvolvimento de protocolos de conduta face a sintomas comuns.

Palavras-chave: Doenças Transmissíveis; Creches.

\section{INTRODUÇÃO}

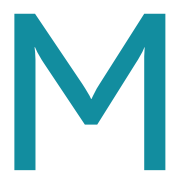

udanças na estrutura social e económica das famílias levaram a que a maior parte das crianças frequente um infantário durante algum período da sua vida. As crian-

*Médica Interna do Internato Médico de Pediatria do Hospital S. Francisco Xavier, Lisboa. **Médica Interna do Internato Médico de Pediatria do Hospital do Barlavento Algarvio, Portimão.

***Assistente de Medicina Geral e Familiar na USF das Conchas, ACES Lisboa Norte e Assistente Livre da Faculdade de Ciências Médicas da Universidade Nova de Lisboa. ças cuidadas em infantários apresentam um risco duas a três vezes superior de adquirir infecções, por comparação com as crianças cuidadas em casa. Este aspecto tem impacto, não só na saúde individual, como na disseminação das doenças à comunidade. ${ }^{1-12}$ Estima-se que os pais de crianças que frequentam infantários se ausentem da sua actividade profissional, em média, uma a quatro semanas por ano, para cuidarem de seus 
filhos doentes. ${ }^{4,7,9,13} \mathrm{~A}$ exclusão de uma criança tem, portanto, custos directos e indirectos. ${ }^{2,3,14,15}$

Existem diversos factores responsáveis pela transmissão de infecções em creches e jardins-de-infância. Por uma questão de conveniência, classificamos esses factores em três grupos: características das crianças, características dos agentes infecciosos e características organizacionais das creches e jardins-de-infância.

Sabe-se que as crianças colocam, em média, a mão ou outro objecto na boca uma vez a cada três minutos, o que facilita a transmissão de doenças. É frequente que algumas infecções se apresentem na forma de doença sub-clínica. Assim, muitas infecções são transmitidas antes de se encontrar o caso índice. . $^{2,4,6,8}$

As características do microrganismo também são importantes: o grau de virulência, a forma de transmissão e a capacidade de sobrevivência no meio ambiente. ${ }^{11} \mathrm{~A}$ disponibilidade de uma vacina é outro factor chave na transmissão de doenças. As infecções mais frequentes nos infantários são as gastrointestinais e respiratórias. ${ }^{1}$ O Vírus Sincicial Respiratório (VSR) e os Rinovírus podem persistir durante horas a dias em superfícies húmidas ou secas de materiais não porosos, como os brinquedos. Agentes de doença gastrointestinal como os Rotavírus, vírus da Hepatite A e B, Giardia lamblia, permanecem infecciosos em superfícies semanas após a contaminação., ${ }^{2,6}$

Dentro das características organizacionais, as técnicas simples de lavagem das mãos são consideradas as mais eficazes para prevenir a transmissão de infecções. Estas devem ser especialmente reforçadas antes da manipulação de alimentos, após a muda de fralda ou ida à casa de banho ou após manipulação de roupas ou objectos contaminados com dejectos ou secreções corporais. ${ }^{2,4,6,15} \mathrm{~A}$ existência de salas de isolamento ou de pessoal especializado para cuidar das crianças doentes, sem comprometer a prestação de cuidados às restantes, poderia constituir uma alternativa e permitiria não afastar a criança da sua rotina habitual; no entanto, isto não acontece na maioria das instituições. ${ }^{9}$

Do ponto de vista teórico, a exclusão escolar é uma das estratégias possíveis para reduzir a transmissão de doenças infecto-contagiosas. No entanto, ela apenas deve acontecer quando ocorra alguma das seguintes premissas: 1) incapacidade da criança para participar nas actividades do infantário; 2) incapacidade do pres- tador de cuidados em tomar conta da criança doente sem comprometer a prestação de cuidados às outras crianças; 3) doença infecto-contagiosa com risco de transmissão a outras crianças ou adultos. ${ }^{3,4,11,13,16}$ Existe, no entanto, alguma controvérsia associada a este último ponto. O período de contagiosidade tem sido usado para definir o período de evicção escolar. No entanto, a bibliografia é frequentemente omissa ou fornece informações discrepantes. Para além disso, para a maioria das doenças infecto-contagiosas, não existe evidência de que a exclusão de crianças com doença respiratória diminua a incidência destas infecções. ${ }^{3}$

Em Portugal, o decreto-lei que regulamenta as doenças e os períodos de evicção escolar remonta a $1995^{17} \mathrm{e}$, desde então, muitos infantários têm criado o seu próprio regulamento interno, exigindo, por vezes, declarações sem fundamento legal. ${ }^{7,16} \mathrm{~A}$ maioria das instituições requer a observação pelo médico antes de a criança regressar ao infantário ou exige declarações após um período de doença. Para além de sobrecarregar os sistemas de saúde, pressionam os médicos a prescreverem inadequadamente antibióticos para as crianças poderem regressar mais depressa à instituição. ${ }^{4,13}$ Noutros países, como, por exemplo, Israel, os Ministérios da Educação e da Saúde estipularam que apenas a ausência por mais de cinco dias requeria declaração médica para regressar ao infantário. ${ }^{4}$

Com este trabalho pretendeu-se:

- Caracterizar os conhecimentos dos educadores de infância e auxiliares de acção educativa sobre medidas de prevenção e transmissão de infecções;

- Identificar quais os sintomas ou doenças que, segundo os educadores de infância e auxiliares de acção educativa, justificam a exclusão escolar.

\section{MÉTODOS}

Foi realizado um estudo não experimental, exploratório, descritivo, transversal, com base em questionário auto-preenchido, aplicado a educadores de infância e auxiliares de educação que exerciam a sua actividade na área de influência do Centro de Saúde do Lumiar e que decorreu de 01/05/2009 a 31/06/2009.

\section{Selecção dos participantes}

Procuraram identificar-se todas as creches e jardins-de-infância da área de influência do Centro de Saúde do Lumiar, através do sítio na internet de equipamentos e 
recursos sociais da freguesia do Lumiar, ${ }^{18}$ lista telefónica e através do contacto com os técnicos de serviço social do Centro de Saúde do Lumiar. Foram enviados, por escrito, convites para participação no estudo a todos os directores das creches/jardins-de-infância e agrupamentos de escolas identificadas e, ainda, ao provedor da Santa Casa da Misericórdia. Nas instituições que aceitaram participar, todos os educadores de infância e auxiliares de educação foram convidados a entrar no estudo.

\section{Construção do instrumento de medida}

Após extensa pesquisa bibliográfica, os investigadores não encontraram questionários ou escalas semelhantes em que se pudessem basear. Assim, optaram por construir um questionário de auto-preenchimento (ver Anexo I) que consiste em perguntas abertas (idade) e fechadas pré-codificadas multicotómicas (restantes).

Para identificação das variáveis do estudo descritivo, realizou-se um pequeno estudo qualitativo prévio num jardim-de-infância fora da área de influência do Centro de Saúde do Lumiar. Procuraram identificar-se conhecimentos, crenças e atitudes face a sintomas e medidas de prevenção de infecções, utilizando uma técnica de grupo nominal ${ }^{19}$ que envolveu, tanto educadoras de infância, como auxiliares de educação. Os temas que surgiram na discussão foram operacionalizados em variáveis e transpostos para questionário. Foi escolhida uma sequência de perguntas de forma a minimizar a influência das perguntas anteriores na resposta às perguntas subsequentes. Não existiu, contudo, pré-teste formal ao questionário.

O questionário consistia em duas partes, a primeira sobre conhecimentos e atitudes face a sintomas e doenças, a segunda sobre características demográficas.

\section{Aplicação do questionário}

De forma a garantir o anonimato das respostas, os únicos dados de identificação eram idade, sexo e escolaridade. A recolha dos questionários ficou centralizada no director da instituição (ou pessoa por ele nomeada), para que não houvesse possibilidade de identificação dos participantes por parte dos autores.

\section{Análise dos dados}

Os dados foram inseridos no programa Microsoft Access 2003 (Microsoft Corp). Foi aplicada estatística des- critiva para tratamento de cada uma das variáveis, utilizando-se o software SPSS for Windows versão 15 (Chicago, SPSS Inc).

Foi definido, a priori, que se excluiriam inquéritos em que a primeira parte (conhecimentos e atitudes) não fosse integralmente preenchida. Uma vez que se pretendia apenas fazer o estudo descritivo dos conhecimentos e atitudes, foi definido que se considerariam válidos os inquéritos com omissões na segunda parte do questionário.

\section{RESULTADOS}

\section{Características dos participantes}

Foram convidadas a participar no estudo 31 instituições públicas, Instituições Particulares de Solidariedade Social (IPSS) e privadas, das quais 24 colaboraram no preenchimento dos inquéritos (12 instituições privadas, oito IPSS e quatro públicas). O número de inquéritos distribuídos pelas instituições foi de 267, dos quais 223 foram devolvidos e 204 estavam totalmente preenchidos. (Figura 1)

Em 16 inquéritos, a idade era omissa, nos restantes a idade média foi de 37,4 anos, com um intervalo entre

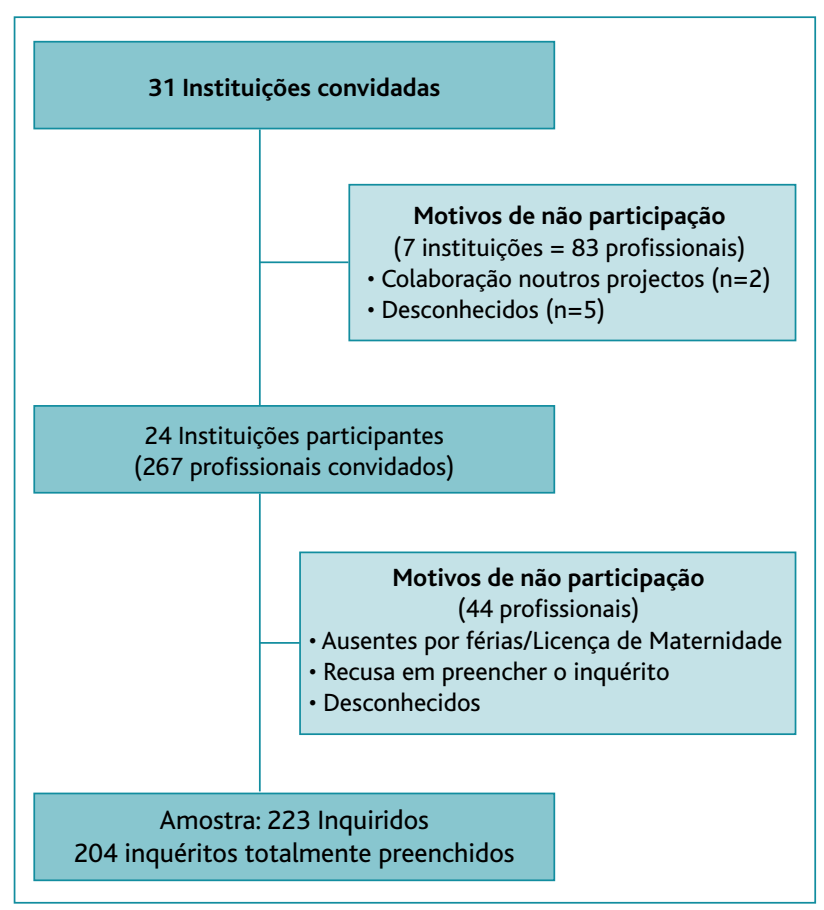

Figura 1. Diagrama de participação. 
20-66 anos. A população estudada era na sua quase totalidade do sexo feminino $(n=215)$; no entanto, em sete inquéritos, a variável sexo era omissa, e registámos apenas um inquirido do sexo masculino.

O estudo da variável grau académico revelou que $56,9 \%(n=127)$ dos inquiridos tinha um curso superior, seguido pelo ensino secundário, 30,9\% $(n=69)$. Da amostra estudada, 5,4\% $(\mathrm{n}=12)$ tinha o ensino básico, 3,1\% $(n=7)$ um curso tecnológico, $1,8 \%(n=4)$ o quarto ano de escolaridade e $1,8 \%(n=4)$ não respondeu a esta questão.

Do total de inquiridos, $112(50,2 \%)$ tiveram formação em doenças contagiosas da infância; no entanto, apenas 56 inquiridos (25\%) tinha conhecimento da existência do decreto regulamentar n³/95, de 27 de Janeiro, ${ }^{17}$ e destes só $35,7 \%(n=20)$ referia conhecer o seu conteúdo. A grande maioria, 97,8\% ( $n=218)$, considerava útil para o seu desempenho profissional a formação em doenças contagiosas da infância.

\section{Caracterização dos conhecimentos sobre medidas de prevenção de transmissão de doenças}

A amostra foi inquirida sobre quais seriam as causas responsáveis por doenças contagiosas na criança; os resultados estão apresentados no Quadro I.

As medidas preventivas são reconhecidas pela maioria dos profissionais, sendo que a lavagem das mãos foi referida por $94,2 \%$, tal como se observa no Quadro II.

Atitudes face a sintomas que, segundo os educadores de infância e auxiliares de acção educativa, justificam a exclusão escolar temporária

\section{Sintomas respiratórios}

No contexto de uma infecção respiratória, a grande maioria dos educadores/auxiliares $(93,3 \%)$ considera que a temperatura rectal igual ou superior a $39^{\circ} \mathrm{C}$ é um factor de exclusão da criança da instituição. No entanto, somente $78,5 \%$ dos inquiridos assinalou a falta de ar como factor justificativo da exclusão escolar. Mais de metade dos inquiridos (52\%) considera a tosse emetizante como critério de exclusão. Adicionalmente, $16 \%$ dos inquiridos assinalaram a rinorreia purulenta, 13\% a temperatura rectal superior a $37,5^{\circ} \mathrm{C}, 7,6 \%$ a tosse seca e $5 \%$ os espirros como razões suficientes para excluir a criança. A presença de várias crianças na mesma sala com sintomas idênticos foi apontada por $52 \%$ dos inquiridos como factor de exclusão.
QUADRO I. Formas de transmissão e factores

apontados como responsáveis por doenças contagiosas da infância.

\begin{tabular}{l|c} 
Formas de transmissão/Motivos & N. $^{\circ}$ de respostas \\
\hline Tosse & $173(77,6 \%)$ \\
\hline Transmissão entre as crianças & $167(74,9 \%)$ \\
\hline Ambiente fechado dos infantários & $161(72,2 \%)$ \\
\hline Espirros & $157(70,4 \%)$ \\
\hline Falta de cuidados de higiene na criança & $143(64,1 \%)$ \\
\hline Transmissão pelos educadores de & $106(47,5 \%)$ \\
\hline infância ou outros profissionais & \\
\hline Fezes & $102(45,7 \%)$ \\
\hline Objectos/paredes do infantário & $80(35,9 \%)$ \\
\hline Diferenças bruscas de temperatura & $66(29,6 \%)$ \\
\hline Ar condicionado & $54(24,2 \%)$ \\
\hline Urina & $51(22,9 \%)$ \\
\hline Suor & $39(17,5 \%)$ \\
\hline Lágrimas & $20(8,9 \%)$ \\
\hline
\end{tabular}

QUADRO II. Medidas consideradas úteis na prevenção de infecções.

\begin{tabular}{l|c}
$\begin{array}{l}\text { Medidas úteis na prevenção } \\
\text { de infecções }\end{array}$ & N. $^{\circ}$ de respostas \\
\hline Lavagem das mãos & $210(94,2 \%)$ \\
\hline $\begin{array}{l}\text { Impedir a frequência de crianças } \\
\text { doentes no infantário }\end{array}$ & $191(85,7 \%)$ \\
\hline Vacinas & $177(79,4 \%)$ \\
\hline $\begin{array}{l}\text { Lavagem diária de brinquedos e } \\
\text { materiais manipulados pelas crianças }\end{array}$ & $128(57,4 \%)$ \\
\hline $\begin{array}{l}\text { Desinfecção das paredes e objectos } \\
\text { do infantário }\end{array}$ & $115(51,6 \%)$ \\
\hline
\end{tabular}

\section{Sintomas gastrointestinais}

Questionámos os nossos inquiridos se diferentes características de sintomas abdominais (diarreia, vómitos e dor abdominal) justificavam a exclusão escolar. Nos casos de diarreia, a presença de sangue foi a mais referida (88,8\% dos educadores/auxiliares), seguida da presença de três dejecções diarreicas consecutivas $(74,4 \%)$ e, por fim, diarreia esverdeada $(44,4 \%)$. No que 
QUADRO III. Doenças que motivam exclusão escolar de acordo com a opinião dos profissionais de educação.

\begin{tabular}{l|c|l|c} 
Doença & N. ${ }^{\circ}$ de respostas & Doença & N. ${ }^{\circ}$ de respostas \\
\hline Meningite & $208(93,3 \%)$ & Tosse Convulsa & $133(59,6 \%)$ \\
\hline $\begin{array}{l}\text { Tuberculose } \\
\text { pulmonar }\end{array}$ & $195(87,4 \%)$ & Hepatite A & $129(57,8 \%)$ \\
\hline Escarlatina & $193(86,5 \%)$ & Tinha & $129(57,8 \%)$ \\
\hline Sarampo & $188(84,3 \%)$ & Infecção urinária & $112(50,2 \%)$ \\
\hline Rubéola & $184(82,5 \%)$ & Poliomielite & $108(48,4 \%)$ \\
\hline Varicela & $179(80,3 \%)$ & Piolhos & $103(46,2 \%)$ \\
\hline Papeira & $174(78 \%)$ & Quinta doença & $85(38,1 \%)$ \\
\hline Conjuntivite & $159(71,3 \%)$ & Impétigo & $56(25,1 \%)$ \\
\hline Gastroenterite & $156(69,9 \%)$ & HIV & $52(23,3 \%)$ \\
\hline Febre tifóide & $155(69,5 \%)$ & Exantema súbito & $49(21,9 \%)$ \\
\hline Escabiose & $151(67,7 \%)$ & Otite & $32(14,3 \%)$ \\
\hline Difteria & $140(62,8 \%)$ & Constipação & $16(7,2 \%)$ \\
\hline Hepatite B & $139(62,3 \%)$ & & \\
\hline
\end{tabular}

Legenda - N. ${ }^{\circ}-$ número.

diz respeito aos vómitos, a incapacidade de tolerar líquidos foi referida como situação suficiente para a exclusão por $76,7 \%$ dos inquiridos, enquanto os vómitos sem má disposição associada foram considerados suficientes por $25,5 \%$ dos inquiridos. Perante a dor abdominal, 49,7\% assinalaram a dor que não pára, enquanto $5,8 \%$ assinalaram a dor que «vai e vem». Adicionalmente, $45,3 \%$ consideraram que a presença de lombrigas leva a exclusão escolar. A presença de vários casos semelhantes de doença gastrointestinal na mesma sala foi apontada por 59,6\% dos educadores/auxiliares como motivo de exclusão.

\section{Sintomas oculares}

O olho colado, um sintoma que preocupa os educadores/auxiliares, foi apontado por $91 \%$ destes como razão para não frequentar a instituição. $\mathrm{O}$ exsudado purulento foi o segundo sintoma ocular mais referido ( $81,2 \%$ dos inquiridos). Foram menos vezes mencionados o olho vermelho $(47,1 \%)$ e o acto de esfregar os olhos $(24,1 \%)$. A presença de várias crianças na sala com sintomas idênticos foi apontada por 52,9\%.

\section{Febre}

A presença isolada de febre (definida como temperatura rectal igual ou superior a $38^{\circ} \mathrm{C}$ ) foi apontada por $78,9 \%$ dos educadores/auxiliares como motivo para não frequentar a creche/jardim-de-infância. A proporção é ainda maior quando não se consegue baixar a febre $(91,9 \%)$ ou se a criança volta a ter febre menos de quatro horas após ter sido administrado paracetamol (83,4\%). Pelo contrário, uma demora em atingir o efeito terapêutico do paracetamol igual ou superior a $30 \mathrm{mi}-$ nutos foi referida apenas por $26,9 \%$ dos profissionais. Curiosamente, quando a criança deixa de comer ou deixa de brincar/participar nas actividades da sala, apenas $19,3 \%$ e $24,2 \%$, respectivamente, achavam que não devia frequentar a instituição.

Atitudes face a doenças que, segundo os educadores de infância e auxiliares de acção educativa, justificam a exclusão escolar temporária

Quando os profissionais foram questionados sobre quais as doenças que justificam exclusão escolar, a meningite foi a mais referida, seguida da tuberculose pulmonar, tal como se observa no quadro III.

No caso particular das doenças exantemáticas, a escarlatina e o sarampo foram apontados como motivo de exclusão escolar pela quase totalidade dos profissionais $(97,8 \%)$, seguidos da rubéola $(96,8 \%)$, da varicela $(86,4 \%)$ e da febre da carraça $(68,6 \%)$. No entanto, quando questionados sobre o impétigo, apenas $24,2 \%$ respondeu que excluía. No que diz respeito a doenças que não exigem exclusão escolar, a quinta doença, o exantema súbito, o eczema, a alergia e a picada de insecto, foram referidas como motivo de exclusão por $46,1 \%, 25,6 \%, 9,4 \%, 5,3 \%$ e $1,8 \%$ dos inquiridos, respectivamente.

\section{DISCUSSÃO}

\section{Discussão metodológica}

A realização do estudo qualitativo prévio permitiunos identificar áreas de preocupação dos educadores de infância e auxiliares de acção educativa que não tinham 
sido identificadas na pesquisa bibliográfica. Procurámos estas áreas de preocupação num conjunto mais alargado de profissionais de educação, tendo utilizado, para isso, um questionário.

Admitimos que o questionário poderá não ser o método ideal para avaliar comportamentos face a sintomas ou práticas para prevenir a transmissão de doenças. Outras formas de recolha de dados (entrevista, videogravação, recolha prospectiva e diária das crianças excluídas em cada uma das instituições e dos motivos que levaram à exclusão) poderiam ter dado perspectivas complementares, ${ }^{20}$ mas não eram exequíveis face aos recursos disponíveis.

No questionário, era perguntado se, face a uma criança com um determinado sintoma, o profissional de educação tomava a decisão de excluir a criança. Este tipo de questão assume que a decisão de exclusão é função de apenas um sintoma. No entanto, é plausível que os profissionais de educação decidam, à semelhança dos profissionais de saúde, com base em «guiões de doença» ou "constelações de sintomas». Assim, apesar de as respostas que obtivemos nos indicarem que existem sintomas mais valorizados que outros, poderão não espelhar o processo de decisão do profissional de educação. Por outro lado, não foram diferenciados o grupo de educadores de infância e o de auxiliares de educação, o que os autores reconhecem que dada a diferença de formação e eventuais conhecimentos, assim como funções que desempenham, poderá ter importância na decisão de excluir temporariamente a criança, o que poderia ter enriquecido o estudo.

Devido a restrições nos recursos ao dispor dos investigadores, não foi possível realizar um pré-teste ao nosso questionário. Em concreto, admitimos que os inquiridos não tenham escolhido algumas opções por desconhecerem o significado das mesmas (por exemplo, o impétigo, a tinha, a poliomielite e a quinta doença).

Nas questões multicotómicas foi pedido que os respondentes assinalassem todas as opções que considerassem válidas. Embora isto tivesse simplificado a resposta ao questionário, levantou dificuldades na análise dos dados. Não nos é possível compreender se a não resposta corresponde a discordância com a frase enunciada ou se o respondente não leu a frase. Isto significa que algumas opções podem estar subvalorizadas. ${ }^{21}$

Para, por um lado garantir que os autores não pudessem identificar os respondentes e, por outro, facili- tar a distribuição e recolha dos questionários, optou-se por centralizar a recolha dos questionários no director da instituição. No entanto, verificámos um conjunto de 19 questionários em que faltavam dados sócio-demográficos, embora as restantes questões estivessem preenchidas. A nossa opção pode ter levantado receios que os directores de instituição pudessem conseguir identificar os inquiridos. Adicionalmente, os respondentes sabiam, à partida, dos objectivos do estudo. Achamos que estes dois factos (receio de identificação pelo director da instituição e conhecimento do objectivo de estudo) poderão ter induzido uma forma de viés de aceitabilidade social. Isto é, os inquiridos podem ter respondido aquilo que acreditavam ser correcto e pode não traduzir o seu real comportamento. Houve o cuidado de identificar todas as creches e jardins-de-infância nesta zona, incluir instituições que fossem públicas, ligadas a instituições particulares de segurança social e do sector privado, o que nos permite ter um retrato bastante completo da nossa realidade local. Não encontramos razões para pensar que os conhecimentos dos educadores de infância e auxiliares que trabalhem em contexto rural ou em cidades mais pequenas sejam diferentes dos que encontrámos no nosso contexto local. Poderá, no entanto, haver diferenças nos comportamentos que estejam relacionadas com a acessibilidade a cuidados de saúde ou com a proximidade entre o local de trabalho dos pais e a creche. Resumindo, admitimos que o nosso questionário possa não ser totalmente adequado para medir uma decisão complexa, poderá haver subvalorização de alguns sintomas ou doenças por desconhecimento do significado das perguntas, poderá haver sobrevalorização de algumas medidas de prevenção da transmissão de infecção pelo viés de aceitabilidade social e as respostas podem espelhar o comportamento desejado e não o comportamento real.

\section{Discussão dos resultados}

\section{Factores envolvidos na transmissão de doença e medidas preventivas}

A generalidade dos factores associados às infecções foi apontada pelos educadores/auxiliares, uma vez que as causas mais referidas foram a tosse, a transmissão entre as crianças, o ambiente fechado dos infantários e os espirros, o que de facto está de acordo com os da- 
dos epidemiológicos. A transmissão a partir das fezes foi assinalada por $45,7 \%$ dos inquiridos, apesar de ser reconhecida, na literatura, como factor importante na contaminação das superfícies. ${ }^{2,3,6,11}$

A lavagem das mãos é a medida para prevenir a transmissão de infecções apontada por um maior número inquiridos (94,2\%), o que está de acordo com alguns estudos que sugerem redução do absentismo escolar e da disseminação de infecções nas instituições. ${ }^{10,12,15}$ No entanto, para as restantes medidas estudadas parece haver discordância entre as convicções dos educadores de infância e auxiliares e a literatura médica. Uma vez que existem bastantes estudos que corroboram a sua eficá$\mathrm{cia}^{2,3,6,11} \mathrm{e}$ dada a popularidade do Programa Nacional de Vacinação no nosso país, esperávamos que a vacinação fosse defendida pela totalidade dos profissionais. Por outro lado, e embora seja conhecido pela classe médica que evitar o acesso de crianças doentes às instituições pode não ser útil para prevenir infecções, ${ }^{14}$ esta medida foi referida por $85,7 \%$ dos inquiridos.

\section{Sintomas}

A proporção de profissionais que excluem a criança só pela febre $(78,9 \%)$ é semelhante à verificada no estudo de Kahan et al $(76,7 \%){ }^{4}$ Um estudo elaborado pelo Children's Medical Center of the University of Virginia revelou que, num inquérito aplicado a infantários, em $43 \%$ destas instituições havia exclusão de crianças com temperatura entre $37,2-37,7^{\circ} \mathrm{C}$. Destas, $31 \%$ responderam que permitiam a permanência da criança com febre e $10 \%$ mantinham a criança em situação de isolamento até à chegada dos pais. Muitas crianças com febre baixa não têm repercussão no estado geral, nem são contagiosas, pelo que, usada como critério isolado, não parece adequada a sua exclusão. ${ }^{13} \mathrm{~A}$ maioria das crianças com febre ligeira não tem uma doença transmissível e consegue participar nas actividades. A febre como factor isolado não será suficiente para excluir a criança, a presença de outros sintomas concomitantes parece servir como critério mais adequado. ${ }^{4}$

No mesmo estudo citado anteriormente, que foi conduzido pelo Children's Medical Center of the University of Virginia, os profissionais de infantários afirmaram que $48 \%$ dos infantários excluem de imediato as crianças se tiverem rinorreia esverdeada. No nosso estudo, apenas $16 \%$ dos inquiridos refere excluir a criança se ela tiver este sintoma. Sabemos que a mudança de cor da rinorreia não deve ser considerada como factor decisor de exclusão, uma vez que a coloração amarelada se deve à presença de polimorfonucleares, enquanto a coloração verde se deve à libertação de mieloperoxidase pelos granulócitos e não necessariamente a infecção bacteriana. ${ }^{13}$

Num estudo efectuado em Israel, ${ }^{4}$ a exclusão da criança por tosse ocorreu em $75 \%$ dos infantários. No inquérito que efectuámos, apenas $7,6 \%$ dos profissionais referiu excluir a criança com tosse seca, mas esta percentagem sobe para $52 \%$ quando a tosse é emetizante.

No que diz respeito aos sintomas oculares, $81,2 \%$ respondeu que a presença de exsudado purulento ocular impedia a criança de frequentar a instituição, percentagem semelhante às referidas noutros estudos (que variou entre 83 e $87 \%)_{.}^{4,13} \mathrm{~A}$ presença de «olho colado" preocupa ainda mais os profissionais, uma vez que $91 \%$ assinalaram esta alínea. A Academia Americana de Pediatria sugere a exclusão de crianças com conjuntivite purulenta até à observação médica e início do tratamento. ${ }^{4}$

Verificámos que $76,7 \%$ dos inquiridos identificaram a importância da ingestão de líquidos quando a criança vomita; por outro lado, apenas $49,7 \%$ da nossa amostra excluíam a criança quando havia queixas de dor abdominal persistente. Este aspecto pode dever-se ao facto de se tratar de uma queixa frequente em idade pré-escolar e existir alguma desvalorização deste sintoma. No estudo realizado em Israel ${ }^{4}$ não houve distinção a nível das queixas gastrointestinais mas, quando inquiridos, apenas os profissionais de um dos infantários referiu não excluir as crianças com vómitos e/ ou diarreia.

Alguns dos dados que obtivemos são, do ponto de vista biomédico, surpreendentes. Nalguns casos, sintomas de gravidade são menos valorizados do que aquilo que esperávamos. No contexto de uma infecção respiratória, os nossos inquiridos parecem valorizar mais a magnitude da febre $(93,3 \%)$ do que a presença de falta de ar $(78,5 \%)$. A presença de sangue na diarreia (88,8\%), habitualmente benigna, é valorizada por um maior número de inquiridos que um sintoma de gravidade potencial como, numa criança com vómitos, a incapacidade de tolerar líquidos. Não podemos estar seguros, contudo, da existência de uma subvalorização destes sintomas. Podemos admitir que a questão não estaria correctamente elaborada. Por outro lado, há sintomas benignos mas muito valorizados. Exemplos dis- 
so são os sintomas oculares que, no topo das preocupações dos nossos inquiridos, são apenas ultrapassados pela febre associada a sintomas respiratórios e pela febre que não responde aos antipiréticos.

É curioso notar que algumas características parecem atribuir novos significados aos sintomas. Apesar de a febre, por si só, ser considerada suficiente para excluir uma criança do seu contexto escolar (78,9\%), essa proporção é ainda maior quando não se consegue baixar a febre $(91,9 \%)$ ou se a criança volta a ter febre menos de quatro horas após ter sido administrado paracetamol $(83,4 \%)$. A dor abdominal constante $(49,7 \%)$ é muito mais valorizada que uma dor que «vai e que vem» $(5,8 \%)$.

\section{Doenças}

Das doenças transmissíveis com indicação para evicção escolar referidas no Decreto Regulamentar $n .^{\circ}$ $3 / 95,{ }^{17}$ o impétigo não parece ser conhecido como causa de exclusão, uma vez que apenas $24,2 \%$ o apontaram. De igual forma, outras doenças (poliomielite, tosse convulsa, difteria e hepatite A) também parecem não ser do conhecimento da totalidade. A maioria destas doenças tornou-se de tal forma rara em Portugal que pode ser desconhecida dos nossos inquiridos.

Existem, no entanto, doenças para as quais não há evidência para a exclusão escolar, como são exemplos a conjuntivite, a quinta doença, o exantema súbito, a pediculose, ${ }^{1}$ e que são assinaladas por alguns profissionais. A pediculose é motivo para exclusão para $46,2 \%$ dos nossos inquiridos, contrapondo a política dos infantários em Israel, em que apenas 6,7\% excluíam crianças infestadas. ${ }^{2}$

Apesar de não estar contemplada no Decreto Regulamentar n. ${ }^{0} 3 / 95,{ }^{17}$ a sarna constitui uma indicação para exclusão escolar até ser realizado o tratamento. ${ }^{1}$ Concordaram com esta indicação $67,7 \%$ dos inquiridos. No que diz respeito à exclusão por gastroenterite, a lei portuguesa é omissa. Segundo recomendações publicadas na literatura, ${ }^{1}$ a exclusão deve acontecer de acordo com o microrganismo responsável, até 24 h após a última dejecção diarreica, nos casos de infecções por Adenovírus, Rotavírus, Calicivírus e até 3 dias depois no caso do vírus de Norwalk.

Os autores consideram preocupante que $23,3 \%$ dos inquiridos refiram que o vírus da Imunodeficiência Humana (VIH) seja causa de exclusão e $62,3 \%$ considerem a hepatite por vírus B como motivo de exclusão. Este facto não é exclusivo dos nossos inquiridos: num estudo do Archives of Disease in Childhood, cinco de 37 instituições referiam excluir crianças com VIH e um terço excluiria crianças com hepatite por vírus B. ${ }^{5}$

\section{Conclusões e recomendações para estudos posteriores}

Alavagem das mãos, como medida de prevenção de infecções, é um gesto interiorizado pelos nossos inquiridos. Será útil perceber porque é que outras medidas, como a desinfecção de superfícies, paredes e brinquedos, não são referidas por igual número de profissionais, apesar de ser cientificamente reconhecida a sua importância.,

Não parece legítimo esperar que educadores de infância e auxiliares de acção educativa tenham conhecimentos aprofundados sobre o significado de sintomas, nem que sejam capazes de fazer diagnósticos. Nessa medida, é compreensível que adoptem uma postura de elevada sensibilidade e baixa especificidade para doença grave. Deste trabalho, pode-se concluir que os sintomas mais valorizados pelos educadores de infância e auxiliares de acção educativa nem sempre coincidem com sintomas valorizados pelos profissionais de saúde. No entanto, mais do que a valorização excessiva de alguns sintomas sem gravidade, parece ser preocupante que nem todos os profissionais de educação reconheçam sintomas de alarme, como a falta de ar ou os vómitos incoercíveis.

Oferecer formação em medidas de prevenção, sintomas comuns e doenças contagiosas da infância é uma estratégia atraente. Neste estudo, os profissionais mostram-se receptivos a esta oferta formativa. No entanto, falta demonstrar que seja uma estratégia eficaz para mudar comportamentos.

Ao nível institucional, poderá ser útil o desenvolvimento de protocolos de actuação face a sintomas comuns. Pelo menos do ponto de vista conceptual, esta medida poderia levar a uma uniformização da actuação nos diversos estabelecimentos e, eventualmente, reduzir a exclusão não justificada. Os centros de saúde, como instituições próximas da comunidade, estão numa posição privilegiada para apoiar o desenvolvimento destes protocolos.

A reprodução de estudos sobre este tema, utilizando fontes de dados diferentes (recolha prospectiva e diária das crianças excluídas) poderia corroborar ou re- 
futar hipóteses que surgiram no decurso deste trabalho. Seria interessante ver se estudos qualitativos feitos noutros contextos identificam as mesmas preocupações que encontrámos no nosso estudo. Outros estudos qualitativos seriam úteis para compreender o que leva os profissionais de educação a valorizar determinados sintomas. Dado que é uma doença comum e que obriga a exclusão, seria útil compreender qual o comportamento dos educadores de infância e auxiliares de acção educativa perante o impétigo. Suspeitamos que não tenham assinalado esta opção no nosso questionário por desconhecerem o termo, pelo que uma alternativa possível seria utilizar fotografias de lesões impetiginadas. Esta hipótese carece de confirmação. A partir dos resultados deste estudo exploratório, seria útil verificar se oferecer formação na área das doenças transmissíveis modifica o comportamento face à exclusão escolar. Este trabalho permite, pela primeira vez em Portugal, levantar hipóteses sobre o que influencia os educadores de infância ou auxiliares de educação na decisão de excluir uma criança da instituição que frequenta.

\section{AGRADECIMENTOS}

Agradecemos à Dra. Paula Broeiro pelo apoio e incentivo à realização deste trabalho e aos seus comentários construtivos.

\section{REFERÊNCIAS BIBLIOGRÁFICAS}

1. Nesti MM, Goldbaum M. Infectious diseases and daycare and preschool education. J Pediatr (Rio J) 2007 Jul-Aug; 83 (4): 299-312.

2. Klein JO. Infectious diseases and day care. Rev Infect Dis 1986 Jul-Aug; 8 (4): 521-6.

3. Aronson SS, Osterholm MT. Infectious diseases in child day care: management and prevention. Summary of the symposium and recomendations. Rev Infect Dis 1986 Jul-Aug; 8 (4): 672-9.

4. Kahan E, Gross S, Cohen HA. Exclusion of ill children from child-care centers in Israel. Patient Educ Couns 2005 Jan; 56 (1): 93-7.

5. Chouillet A, Maguire H, Kurtz Z. Policies for control of communicable disease in day care centers. Arch Dis Child 1992 Sep; 67 (9):1103-6.

6. Robinson J. Infectious diseases in schools and child care facilities. Pediatr Rev 2001 Feb; 22 (2): 39-46.

7. Davis JP, Mac Kenzie WR, Addiss DG. Recognition, investigation, and control of communicable-disease outbreaks in child day-care settings. Pediatrics 1994 Dec; 94 (6 Pt 2): 1004-6.

8. Osterholm M. Infectious disease in child day care: an overview. Pediatrics 1994 Dec; 94 (6 Pt 2): 987-90.

9. Giebink GS, Chang A, Koch PD, Murray DL, Gonzalez GD. Care of mildly ill children in the day-care setting. Pediatrics 1994 Dec; 94 (6 Pt 2): $1112-4$.
10. Rosen L, Zucker D, Brody D, Engelhard D, Manor O. The effect of a handwashing intervention on preschool educator beliefs, attitudes, knowledge and self-efficacy. Health Educ Res 2009 Aug; 24 (4): 686-98.

11. Mink $C$, Yeh S. Infections in child-care facilities and schools. Pediatr Rev 2009 Jul; 30 (7): 259-69.

12. Kotch J, Weigle KA, Weber DJ, Clifford RM, Harms TO, Loda FA, et al. Evaluation of an hygienic intervention in child day-care centers. Pediatrics 1994 Dec; 94 (6 Pt 2): 991-4.

13. Pappas D, Schwartz RH, Sheridan MJ, Hayden GF. Medical exclusion of sick children from child care centers: a plea for reconciliation. South Med J 2000 Jun; 93 (6): 575-8.

14. Richardson M, Elliman D, Maguire H, Simpson J, Nicoll A. Evidence base of incubation periods, periods of infectiousness and exclusion policies for the control of communicable diseases in schools and preschools. Pediatr Infect Dis J 2001 Apr; 20 (4): 380-91.

15. Sandora TJ, Shih MC, Goldmann DA. Reducing absenteeism from gastrointestinal and respiratory illness in elementary school students: a randomized, controlled trial of an infection-control intervention. Pediatrics 2008 Jun; 121 (6): e1555-62.

16. Copeland KA, Harris EN, Wang NY, Cheng Tl. Compliance with American Academy of Pediatrics and American Public Health Association illness exclusion guidelines for child care centers in Maryland: who follows them and when? Pediatrics 2006 Nov; 118 (5): e1369-80.

17. Decreto Regulamentar $n^{\circ} 3 / 95$ de 27 de Janeiro de 1995. Diário da República I Série B. p. 500-1.

18. Guia de equipamentos e recursos sociais. Disponível em: http://www.jflumiar.pt [acedido a 15/04/2009].

19. Van de Ven AH, Delbecq AL. The nominal group as a search instrument for exploratory health studies. Am J Public Health 1972 Mar; 62 (3): 337-42.

20. Abramson J, Abramson ZH. Research methods in community medicine: surveys, epidemiological research, programme evaluation, clinical trials. 6th ed. Chichester:Wiley; 2008. p. 143-50.

21. Cumming SR, Hulley SB. Designing questionnaires and interviews. In: Hulley SB, Cummings SR, BrownerWS, Grady DG, Newman TB, editors. Designing clinical research. 3rd ed. Philadelphia: Lippincott Williams \& Wilkins; 2007. p.241-55.

\section{CONFLITOS DE INTERESSE}

O autor Bruno Heleno é editor da Revista Portuguesa de Clínica Geral e declara não ter estado envolvido no processo de decisão editorial deste artigo.

\section{ENDEREÇO PARA CORRESPONDÊNCIA}

Paula Nunes

Serviço de Pediatria

Hospital S. Francisco Xavier

Estrada do Forte do Alto do Duque

1400 Lisboa

pasdenunes@gmail.com

Recebido em 25/05/2010

Aceite para publicação em 23/11/2010 


\section{ABSTRACT}

\section{KNOWLEDGE ABOUT TEMPORARY SCHOOL EXCLUSION IN CHILD DAY CARE CENTERS AT LUMIAR HEALTH CENTER'S AREA OF INFLUENCE}

Objectives: Describe the childhood educators and teaching assistants' knowledge about infection prevention measures. Identify symptoms or diseases that, according to these professionals, merit temporary school exclusion.

Design: Non-experimental, exploratory, descriptive, transversal.

Setting: Child day care centers at the Lumiar Health Center's (Lisbon, Portugal) area of influence.

Population: Childhood educators and teaching assistants.

Methods: A self-administered questionnaire was applied to childhood educators and teaching assistants working at Lumiar Health Center's area of influence in the period from 01/05/2009 to 31/06/2009.

Results: Of the 31 invited institutions, 24 agreed to participate ( 267 professionals). 223 questionnaires $(83,5 \%)$ were correctly completed, the average age of the study population was 37.4 years, $50.2 \%$ reported having received training in communicable childhood diseases. The most pointed cause for communicable diseases was under ventilated child day care centers $(72.2 \%)$. Hand washing was reported by $94.2 \%$ staff members as a preventive measure against infection. Fever that does not resolve with antipyretics was considered by $91.9 \%$, a factor of exclusion. Shortness of breath is not considered a reason for exclusion by $21.5 \%$ of the inquired persons. Bloody diarrhea was the most gastrointestinal symptom cited, in $88.8 \%$. Scarlet fever and measles were reported by $97.8 \%$ of staff members as a reason for exclusion. The most exclusion obligatory disease mentioned was meningitis (93.3\%).

Conclusions: The symptoms more valued by the education professionals do not always coincide with those that the health professionals value the most, a factor which could conduce to unjustified school exclusion It may be useful to develop management guidelines for common symptoms at an institutional level.

Keywords: Communicable Disease Control; Child Day Care Centers. 


\section{ANEXO I \\ INQUÉRITO SOBRE EXCLUSÃO ESCOLAR E DOENÇAS CONTAGIOSAS DA INFÂNCIA}

Os profissionais de educação estão em contacto directo com as crianças e por vezes são os primeiros a notar que a criança está doente. $\mathrm{O}$ objectivo deste inquérito é averiguar as dificuldades em sintomas frequentes da infância, sentidas pelos Educadores e Auxiliares de acção educativa, quando as crianças adoecem com infecções agudas.

Este seu contributo será seguido de uma sessão de formação sobre doenças que obrigam a evicção escolar se assim se achar necessário.

Este inquérito é anónimo. Ficamos-lhe desde já agradecidos pela sua colaboração.

1. No seu percurso académico alguma vez teve formação em doenças contagiosas da infância?
a) $\operatorname{Sim}$
b) Não

2. Acha útil para o seu desempenho profissional uma formação nesta área?
a) $\mathrm{Sim}$
b) Não

3. Existe um decreto regulamentar publicado no diário da república em 1995 sobre as doenças que obrigam a evicção escolar.
a) Tem conhecimento da sua existência
a) $\operatorname{Sim}$
b) Não

b) Se respondeu sim à questão anterior. Conhece o seu conteúdo?
a) $\mathrm{Sim}$
b) Não

4. Assinale as causas que considera responsáveis pelas doenças contagiosas nas crianças? (pode assinalar mais do que uma)

a) Ambiente fechado dos infantários

b) Ar condicionado

c) Cócós

d) Diferenças bruscas de temperatura

e) Espirros

f) Falta de cuidados de higiene na criança

g) Lágrimas

h) Objectos/paredes do infantário

i) Suor

j) Tosse

k) Transmissão entre as crianças

l) Transmissão pelos educadores de infância ou outros profissionais

m) Xixis
5. Qual/Quais as medidas que considera eficazes para evitar infecções? (pode assinalar mais do que uma)

a) Lavagem das mãos

b) Impedir a frequência das crianças doentes no infantário

c) Desinfectar as paredes e objectos do infantário

d) Vacinas

6. Do seguinte conjunto de sintomas respiratórios qual/quais pensa que impedem a criança de frequentar a creche/jardim de infância? (pode assinalar mais do que uma)
a) Espirrar
b) Falta de ar
c) Ranho verde
d) Temperatura de $37,5^{\circ} \mathrm{C}$ (medida no rabinho)
e) Temperatura de $39^{\circ} \mathrm{C}$ (medida no rabinho)
f) Tosse seca
g) Vómito com a tosse
h) Várias crianças na mesma sala com os mesmos sintomas
i) Outros

7. Do seguinte conjunto de sintomas do estômago e intestinos qual/quais pensa que impedem a criança de frequentar a creche/jardim de infância? (pode assinalar mais do que uma)

a) Diarreia pelo menos três vezes seguidas

b) Diarreia com sangue

c) Diarreia esverdeada

d) Vómitos sem má disposição associada

e) Quando vomita e não aceita líquidos

f) Lombrigas

g) Dor de barriga que não pára

h) Dor de barriga que vai e vem

i) Várias crianças na mesma sala com os mesmos sintomas

j) Outras

8. Das seguintes doenças que causam manchas/borbulhas na pele qual/quais pensa que impedem a criança de frequentar a creche/jardim de infância? (pode assinalar mais do que uma)

a) Escarlatina

b) Exantema súbito

c) Febre da carraça

d) Quinta doença

e) Rubéola

f) Sarampo 

g) Picada de insecto
h) Varicela
i) Impétigo
j) Alergia (Pele vermelha com comichão)
k) Eczema
l) Outras

9. Na sua opinião, em que situações uma criança com uma conjuntivite não deve frequentar a creche/jardim de infância? (pode assinalar mais do que uma)
a) Esfregar os olhos
b) Olhos vermelhos
c) «Ramelas» verdes
d) Olho colado
f) Várias crianças na mesma sala com sintomas
g) Outras

10. Na sua opinião, em que situações uma criança com febre não deve frequentar a creche/jardim de infância? (pode assinalar mais do que uma)
a) Quando tem mais de $38^{\circ} \mathrm{C}$ no rabinho
b) Demora mais de 30 minutos até o Ben-U-Ron ${ }^{\circledR}$ fazer efeito
c) Volta a ter febre menos de 4 h após ter tomado o Ben-U- $-\operatorname{Ron}^{\circledR}$
d) Não se consegue baixar a febre
e) Quando deixa de comer
f) Quando deixa de brincar / participar nas actividades da sala
g) Várias crianças na mesma sala com sintomas
h) Outras

11. Da seguinte lista de doenças assinale as doenças que justificam evicção escolar? (pode assinalar mais do que uma)
a) Conjuntivite
n) Otite
b) Constipação
o) Papeira
c) Difteria
p) Piolhos
d) Escarlatina
q) Poliomielite
e) Exantema súbito
r) Quinta doença
f) Febre tifóide
s) Rubéola
g) Gastroenterite
t) Sarampo
h) Hepatite $A$
u) Sarna
i) Hepatite $B$
v) Tinha
j) HIV
w) Tosse convulsa
k) Impétigo
x) Tuberculose pulmonar
l) Infecção urinária
y) Varicela
m) Meningite
z) Outras

12. Idade em anos

$\begin{array}{lll}\text { 13. Sexo a) } F & \text { b) } M\end{array}$

14. Grau Académico:
a) $4 .^{\circ}$ ano de escolaridade
b) Ensino Secundário
c) Curso tecnológico
d) Ensino superior

Muito obrigada pela sua colaboração! 